\title{
A Confliet Model for Strategists and Managers
}

GREGORY B. MARKUS

RAYMOND TANTER

University of Michigan

The study of intranation political conflict has received a great deal of attention in recent years. Various models-sometimes explicitly specified but often left implicit in the research-have been employed in attempts to explain the causes and consequences of internal instability. This paper outlines a model of conflict behavior within nations which reflects the idea that a behavior of such complexity can be understood only through a multidisciplinary approach. That is, a synthesis of a number of models is necessary to explain instability behavior or, for that matter, any other form of conflict behavior (compare Fink, 1968; Mack and Synder, 1957).

Authors' Note: This research was supported by the Advanced Research Projects Agency of the Department of Defense and was monitored by the Office of Naval Research under Contract N00014-67-A-0181-0041. The views and conclusions contained in this document are those of the authors and should not be interpreted as necessarily representing the official policies, either expressed or implied, of the Advanced Research Projects Agency or the U.S. government. The authors thank Ted. R. Gurr and Detlof von Winterfeldt for perceptive criticism of earlier drafts. 
Further, the authors consider conflict from the point of view of both the strategist-who seeks to engage in conflict behavior to obtain a specified goal or set of goals-and the manager-the actor desiring to limit the scope or intensity of conflict behavior. It is important that the term "strategist" not be interpreted as being equivalent to "insurgent," "civilian," or "revolutionary." Nor is "manager" a term to denote only political authority or government. At times, it may be civilian groups who attempt to manage the level of conflict, just as it may be persons of authority who seek to engage in violence. Terry Nardin (1971: 15) points out that conflict management need not be biased toward the maintenance of the status quo:

Indeed, because of the greater access of topdogs to the means of coercion, their capacity for violence usually far exceeds that of the underdogs. Violence may indeed be yet another of the privileges of rank. If most of the violence in conflicts between topdogs and underdogs is committed by the topdogs, then conflict management being the limitation of all violence, cannot be seen as prima facie favoring the topdogs. The equation of conflict management with the suppression of discontent, protest, and radical political action is not the inevitable consequence of valuing "negative peace," but follows rather from a conceptual confusion about the nature and causes of political violence.

The model presented here is a statement of the calculus which members on either side of a conflict situation could evaluate prior to their actions. Hence, the model is applicable for both strategists and managers (compare Leites and Wolf, 1970).

\section{THREE APPROACHES TO THE STUDY OF CONFLICT BEHAVIOR}

\section{THE INSTINCTIVE EXPLANATION OF AGGRESSION}

Some authors, such as Konrad Lorenz (1966) and Robert Ardrey (1966, 1961) regard human aggression (of which 
political turmoil is a part) as stemming from an instinctive drive. States Lorenz (1966: x): "Aggression . . . is an instinct like any other and in natural conditions it helps just as much as any other to ensure the survival of the individuals and the species." Ethologists maintain that stimuli may enhance aggressiveness but are not necessary for its manifestation. Aggressive behavior will occur even in the absence of external cues. This essential spontaneity of the aggressive instinct renders measures against its damaging effects of no value. "The most promising means we can apply in our attempt to cope with the miscarrying of aggression-and that of other patterns of social behavior-are those which have proved their efficiency in the course of phylogenic and cultural evolution" (Lorenz, 1966: 278). Lorenz suggests redirection of aggression in to sports and other forms of activity.

\section{FRUSTRATION-AGGRESSION MODELS}

In contrast to the instinctive drive view of aggression are the stimulus-response models, the most notable of which was originated by Dollard et al. (1939). A basic postulate of their frustration-aggression model is that aggression is always the consequence of frustration. Aggression is any act "the goal response of which is the injury of the person toward whom it is directed," and frustration is an interference with the occurrence of an instigated goal-response at its proper time in a behavior sequence (Dollard et al., 1939: 1-9).

Dollard et al. (1939: 1) hypothesized originally that the occurence of aggressive behavior assumes the existence of frustration and that the existence of frustration necessarily leads to some form of aggression. Misinterpretation of this sweeping statement caused Miller (1941: 338) to rephrase the latter portion of the hypothesis thusly: "Frustration produces instigations to a number of different types of response, one of which is an instigation to some form of aggression." Thus, the model does not imply that frustration always leads to direct, overt aggressive behavior. Rather, the hypothesis states that 
when aggressive behavior does occur, it is the result of frustration (see Berkowitz, 1969: 68-69, 1965, 1962; Buss, $1961)$.

The frustration-aggression model has been a popular framework for the study of domestic conflict. As Feierabend et al. (1969: 635-637) point out, one source of "systemic frustration" within a nation is a gap between the aspirations and expectations of individuals or groups on the one hand, and the achievements that actually occur (see Gurr, 1970, 1968a, 1968b). Samuel Huntington (1968: 53-54), in his discussion of political turmoil within developing nations, comments:

Urbanization, literacy, education, mass media, all expose the traditional man to new forms of life, new standards of enjoyment, new possibilities of satisfaction.... The ability of a transitional society to satisfy these new aspirations, however, increases much more slowly than the aspirations themselves. Consequently, a gap develops between aspiration and expectation.... This gap generates social frustration and dissatisfaction. In practice, the ex tent of the gap provides a reasonable index to political instability.

The frustration-aggression model has also been employed by William Kornhauser (1959) in his discussion of extremist voting, by Daniel Lerner (1963), who based some of his work dealing with modernization on the concept of deprivation felt by the masses, and by Hadley Cantril (1965). Similar recognition of the frustration-aggression explanation of political instability can be found in the works of Davies (1962), Gurr (1970), Russett (1964), and Tanter and Midlarsky (1967).

One can see in the instinctive-drive and frustration-aggression models a crucial disagreement as to the cause of aggressive behavior. On the one hand, ethologists argue that aggression is a drive as innate, as natural, and as powerful as sex (Storr, 1968: 109); on the other, Dollard and like-minded theorists maintain that if frustrating stimuli are removed, aggression will not occur. Anthony Storr (1968: 109), whose bias is evident in the following quote, voices the difference between these two perspectives. 
It is vitally important that we finally discard the kind of futile optimism which is implicit in the frustration-aggression hypothesis, and face the fact that, in man, as in other animals, the aggressive drive is an inherited constant, of which we cannot rid ourselves, and which is absolutely necessary for survival.

Both approaches are similar, however, in that they neglect the rational, conscious aspect of political man. Domestic conflict does not stem totally from instinctive drives. Nor is it solely a response to perceived frustrations. Individuals or groups often engage in aggression because they have found such behavior rewarding (Bandura et al., 1963) or necessary for the attainment of a particular goal. Herbert Kelman (1965:6) writes, for example, "While war does involve aggressive behavior on the part of many individuals, this behavior is not necessarily at the service of aggressive motives. Leaders may engage in aggressive behavior for strategic reasons, for example, and the population at large for reasons of social conformity."

Moreover, discontent and dissatisfaction are continually present somewhere within every society. An awareness of these conditions is certainly necessary to an understanding of conflict behavior, but it does not constitute in itself an adequate explanation. To ascertain why discontent leads to violence in some instances and to nonviolent bargaining in others, one must examine the ability of bargaining conditions to endow certain kinds of tactics with efficiency in enhancing future bargaining power to achieve all kinds of values (Nieburg, 1969: 44). Thus, conflict behaviors of varying intensities may be viewed by actors as potential tactics which may be utilized or rejected depending upon their probabilities of success given a particular goal or series of goals, plus certain other information.

\section{DECISION-MAKING MODELS}

A third approach to the study of conflict conceives of the actors involved as being rational decision makers. Conflict, from this point of view, is rooted neither in instincts nor in psychological frustrations. Rather, as Jessie Bernard (1957: 38) 
states: "Conflict arises when there are incompatible or mutually exclusive goals or aims or values expressed by human beings" (see also Boulding, 1962; Axelrod, 1970). Employing rationalchoice models in the analysis of noneconomic social behavior is hardly new. John Harsanyi (1969), for example, argues that both the interest-group assumptions of domestic politics and the national-interest conception of international politics are, in effect, imprecise and informalized versions of a broad rationalchoice approach. The same may be said of the Marxist theory of class in terest (compare Olson, 1968: 102-110).

In the area of conflict management, rational-choice considerations may be found in the work of a number of authors. Scott (1970), for instance, uses an explicitly economic approach in his study of insurgency. Leites and Wolf (1970) similarly employ cost-benefit analysis in a cogent discussion of rebellion and counterinsurgency. H. L. Nieburg (1969, 1963, 1962) has long argued that violence within a conflict often has a rational basis. Ted Gurr (1970: esp. 210-223) also recognizes the value of taking the utility of violence into account in an analysis of conflict. Rational choice models have, of course, been employed most rigorously in the fast-growing area of experimental gaming, and game theory is a fruitful source for the development of both normative and descriptive models of conflict behavior (see Luce and Raiffa, 1957; Davis, 1970; Rapoport, 1970, 1966, 1960).

Although formal decision theory can be quite esoteric, the fundamental ideas underlying this approach are intuitively appealing. It is these basic propositions which we shall touch upon here; for a more complete introduction, the reader is advised to consult, for example, Luce and Raiffa (1957), Edwards and Tversky (1967), Savage (1954), or Edwards et al. (1965).

The most crucial concept of decision theory is that of rationality. Simply stated, a definition of rationality has two parts. First, rationality is the ability to order available alternative outcomes and consistently choose the more preferred over the less preferred options. Second, a rational man makes his 
choices in such a way as to maximize something. Most decision theories assume that the actor maximizes utility, or (under certain conditions) expected utility.

In conflict situations, however, it is not enough for an actor to consider only his actions, for the outcome will depend generally on what his opponent does. The theory of games focuses upon the various strategies open to rational actors in conflict (Luce and Raiffa, 1957; Rapoport, 1970, 1966, 1960; Davis, 1970). A strategy is simply a set of guidelines an actor establishes which determine how he will respond should his opponent act in any given way. Game theorists offer rules to use in choosing among competing strategies.

The game theoretic approach to conflict is attractive for a number of reasons. Formal models of conflict which employ principles of game theory can be developed and studied in the context of controlled laboratory experiments. The value of such a model is the level of generality it possesses due to its freedom from having to take into account the idiosyncracies of any actual situation. By excluding these perturbations from its framework, the model achieves what is sometimes called "elegance."

A price is paid for this elegance, however. Models structured in a game theoretic manner are, by themselves, inadequate to explain most aspects of human conflict. For the concepts and insights of game theory to lead to a fruitful descriptive theory of conflict, they must be integrated into a broader framework. As Anatol Rapoport (1966: 206) notes, in formal game theory there is no room for the psychological make-up of the participants.

To the extent that psychological matters are allowed to enter a theory of conflict, the theory ceases to be a model of rational conflict. Its mathematical apparatus must then include parameters, so that conflict behavior would depend on these parameters. The theory would become a behavioral theory, and real behavior can never be explained on the basis of concepts of "rationality" alone. At least "rationality" must be modified to a relative concept to be put into specific psychological contexts. 
Another shortcoming of game theory is that it is generally limited to the analysis of decision-making under conditions of complete uncertainty. That is, an actor is assumed to have absolutely no information about the relative likelihood of possible outcomes. Moreover, an actor is assumed to possess perfect knowledge regarding his opponents' utility functions and regarding the outcome once he and his opponents have chosen strategies. These assumptions may be unnecessarily restrictive in many instances. An alternative model-the subjectively expected utility (SEU) model-offers another approach. Although the SEU model is typically employed to study games against nature, it may be a not entirely unrealistic model of decision-making within a conflict.

Leonard Savage (1954) was among the first to argue for a decision system which allows the decision maker to utilize whatever information he may possess in order to establish a subjective (or personal probability distribution concerning possible states of nature. Subjective probabilities have mathematical properties similar to those of "objective" probabilities, but there is an important difference. A subjective probability is simply a number that represents the extent to which an individual thinks that a given event is likely (Edwards, 1961). Once a subjective probability distribution has been developed (and Savage axiomatically derives a method for doing so), the problem is transformed essentially into an exercise in decisionmaking under risk. The actor still does not know for sure what will happen if he acts in a given way, but he can make certain probability statements about alternative outcomes.

In the theory of risky decision-making, the actor is assumed to maximize his subjectively expected utility (SEU; Edwards, 1961, 1955; Savage, 1954; Luce and Raiffa, 1957: 299-306). The SEU maximization principle stems from the traditional mathematical notion of the expected value of a game of chance. The expected value of a bet is obtained simply by multiplying the value of each possible outcome, $o_{i}$, by the corresponding probability of occurrence, $p_{i}$, and then summing these products across all outcomes. Symbolically: 


$$
E V=\sum_{i=1}^{n} o_{i} p_{i}
$$

To give a simple example, suppose that you were offered the following bet: Roll a "fair" die; if a one or two comes up, you win $\$ 3.00$; if any other number occurs, you lose $\$ 2.00$. Should you take the bet? To answer this question, you must calculate the expected value of the offer to determine whether this value is favorable to you. The probability of obtaining a one or a two is, obviously, $2 / 6$. Therefore, the probability of obtaining any other number is $1-2 / 6$, or $4 / 6$. The EV (expected value) is thus computed:

$$
\begin{aligned}
\mathrm{EV} & =2 / 6(\$ 3.00)+4 / 6(\$ 2.00) \\
& =\$ 1.00-\$ 1.33 \\
& =-\$ .33
\end{aligned}
$$

The expected value of the bet is negative, a rather unattractive situation. Therefore, being the expected value maximizer you are, you refuse the bet.

Making decisions about whether and how to act in a conflict situation is obviously a more complex affair. The value of an outcome must be replaced by the notion of utility. One must determine how much utility, however measured, one attaches to various alternative outcomes. Moreover, the probabilities of the occurrence of possible events are not nearly so precisely known; they must be estimated subjectively. Thus, in the SEU model, the utilities of possible outcomes must be multiplied by subjective probabilities, and it is the resultant subjectively estimated utility which must be maximized.

To some, the notion of strict maximization is immediately objectionable, and in many instances it does appear to be unrealisitc. As Ward Edwards (1954a: 381-382) argues, however, "assumptions about maximization only become specific, and therefore possibly wrong, when they specify what is being maximized." Riker and Ordeshook (1968: 27) point out that it 
is common for theorists to impose their own interpretation of goals upon observed behavior (compare Shapiro, 1969). The act of voting, for example, may appear irrational if one assumes that the only goal is to elect a candidate to office; the costs of voting almost always outweigh the probable influence of one vote (Downs, 1957). However, if other benefits are taken into account-such as feelings of patriotism, group identity, political efficacy-then voting may often be rational. That is, the utility of voting, particularly from a sociological and psychological point of view, may often outweigh the costs involved.

Similarly, Rapoport (1960: 121) notes that there is more in winning a poker game than simply the amount in the pot.

There is the jingling of the coins, the admiration of the onlookers, the feeling of being "lucky," etc. Perhaps if all of these things are taken into account in some way, the gambling behavior (and more generally all risk behavior) of people can be explained in terms of maximizing some quantity. And if this quantity is different in different people but can be determined for each person or for each class of people, it seems worthwhile to try to do so; the discovery would be an important psychological finding.

Whenever multiple motives are allowed to enter into the decision model, however, one must confront the problem of potential circularity. Many social scientists oppose the use of rational-choice models because, given enough parameters, one can "prove" that any decision is "rational." This problem, these social scientists would argue, becomes particularly apparent when one tries to "explain" why an action was rational after it has already occurred. Indeed, the popular term "rationalize" was coined to emphasize the circularity involved in such a process. Harsanyi (1969) clearly points out, however, that so long as the number of parameters we hypothesize are both relatively few and theoretically plausible, then circularity is not a problem. He continues:

We must definitely resist the temptation of postulating more than a very few basic motives in our theory, whether for the sake of "greater realism" or for any other reason. This is so because a theory 
involving a large number of distinct motives, and therefore involving a large number of parameters to be estimated from the empirical facts, cannot be used to explain these empirical facts without inadmissible circularity. This is of course just another way of saying that if our theory is to have any real explanatory power then our motivational assumptions must be kept at a very low level of complexity-even if they do not have to be made quite as simple as to postulate economic self-interest as the only important motive of human behavior [Harsanyi, 1969: 521; italics in original] .

\section{A CONFLICT MODEL: SYNTHESIZING COMPLEMENTARY APPROACHES}

What is proposed, then, is a model of conflict behavior which takes into account a number of aspects of such behavior. The model will stress the rational nature of decision-making in conflict situations. This approach, however, will not neglect the psychological and sociological factors important to an understanding of conflict.

One assumption of the present work is that conflict is rooted, at least in part, in an incompatibility of the goals or aims of two or more sets of actors. Hence, the model contains terms referring to the goal-related costs and benefits associated with engaging in various conflict behaviors. If:

$\mathrm{B}_{\mathrm{g}}$ : the benefit an actor receives from obtaining specified goal, $g$;

$\mathrm{P}_{\mathrm{g}}$ : the subjectively estimated probability that the conflict behavior will bring about $\mathrm{B}_{\mathrm{g}} ; 0 \leqslant \mathrm{P}_{\mathrm{g}} \leqslant 1$;

$A_{j}$ : the costs of engaging in a conflict behavior which are due to an opponent's response, $j$;

$P_{j}$ : the subjectively estimated probability of opponent's response, $j ; 0 \leqslant \mathrm{P}_{\mathbf{j}} \leqslant 1$;

$\mathrm{n}$ : the number of specified goals, $g$;

$\mathrm{m}$ : the number of possible opponent's responses, $j$;

$\mathrm{C}_{\mathrm{i}}$ : the costs of engaging in the conflict behavior which are independent of the opponent's response;

then, SEU, the subjectively expected utility of engaging in a particular conflict behavior, can be expressed thusly: ${ }^{1}$ 


$$
\operatorname{SEU}=\left(\sum_{\mathrm{g}=1}^{\mathrm{n}} \mathrm{B}_{\mathrm{g}} \mathrm{P}_{\mathrm{g}}-\sum_{\mathrm{j}=1}^{\mathrm{m}} \mathrm{A}_{\mathrm{j}} \mathrm{P}_{\mathrm{j}}\right)-\mathrm{C}_{\mathrm{i}}
$$

From the equation, it is evident that multiple goals, each associated with some benefit, may exist. Each goal, in turn, is associated with a subjective probability, $P_{1}, P_{2}, \ldots, P_{n}$, that a specific conflict behavior will result in the realization of the goal (compare Wilson, 1961). Similarly, probabilities are associated with costs due to the opponent's retaliatory measures. Probabilities associated with costs and benefits may, of course, be closely related. The probability that an action will achieve a certain goal, for example, may often be related to the probabilities that it will evoke certain retaliatory responses. The term $C_{i}$ consists of such costs as resource outlays (both time and material), costs due to foregone alternatives, and other costs which must be absorbed regardless of the outcome of the conflict. According to the model, an actor would evaluate the costs and benefits associated with the possible conflict behaviors in which he might engage and choose that behavior with the greatest net utility. The process of in teraction between actors in conflict is assumed to be composed of discrete decision points. The SEU model denotes the static decision process undertaken at each decision point. In this regard, this approach considers conflict as a series of alternating decisions among actors.

As a rather elementary example, consider an instance in which a revolutionary group seeks to raise funds or supplies with which to strengthen themselves. ${ }^{1}$ The cadre has before them two plans from which they must choose. One plan is to kidnap a government leader and hold him for $\$ 1,000,000$ ransom. An alternative scheme is to ambush a military convoy carrying $\$ 1,000,000$ worth of munitions in two trucks. ${ }^{2}$

In the past, six kidnapping attempts have been made, of which three have been successful (that is, have secured a ransom without the participants being captured). In the other instances, the abductors have been sentenced to long prison terms. Possessing no other information, the rebels set their best 
estimate of the probability of success at .5. In terms of resource outlays, the rebels estimate that a kidnap attempt will cost $\$ 5,000$, to cover such expenses as weapons, bribes, hideouts, and time lost while in hiding. The SEU of a kidnap attempt is calculated:

$$
\begin{aligned}
\text { Let } C & =\text { capture. } \\
\text { SEU }_{1} & =(\$ 1,000,000)(.5)-[(.5) C+(.5)(0)]-\$ 5,000 \\
& =\$ 495,000-.5 \mathrm{C}
\end{aligned}
$$

The SEU of an ambush attempt is calculated similarly. The rebels estimate that they have a $20 \%$ chance of securing both trucks of munitions and a 50\% chance of securing one truckload. There is, however, a $30 \%$ chance of their being captured. An estimated $\$ 10,000$ in resources would be necessary to undertake the ambush. The SEU, then, is:

$$
\begin{aligned}
\mathrm{SEU}_{2} & =[(\$ 500,000)(.5)+(\$ 1,000,000)(.2)]-[(.3) \mathrm{C}+(.7)(0)]-\$ 10,000 \\
& =\$ 440,000-.3 \mathrm{C}
\end{aligned}
$$

By comparing $\mathrm{SEU}_{1}$ and $\mathrm{SEU}_{2}$, the rebels can see that the kidnap offers a greater expected return than does the ambushbut at a $20 \%$ greater chance of capture. If they decide that the added likelihood of capture is worth the extra expected gain, they should choose the kidnap plot. If not, they should decide to ambush the convoy.

The model of decision-making in a conflict situation illustrated above is not as unrealistic as it may appear at first blush. Although strategists and managers may not perform the calculations as explicitly as depicted, there is reason to believe that actors in conflict situations often bear in mind the expected costs and benefits of alternative actions. As Abdul Nasution (1965: 21) asserts in Fundamentals of Guerrilla Warfare: "A guerrilla must fight with ... economy ... he must calculate his gains and losses like a good businessman." Andrew Scott has devised a similar model of insurgency. He notes (1970: 40) that "the stakes for a participant may be thought of 
as the gains that he would derive from victory relative to the losses that would be associated with defeat."

The model may be particularly suggestive in regard to the behavior of leaders within the context of a conflict, and by our stress on "strategists and managers" we have been implicitly emphasizing the conduct of individuals in roles of leadership. Gurr (1970: 211) writes:

Men make more or less explicit calculations about the prospective benefits vis-a-vis the prospective costs of violence as a tactic. Such calculations are likely to be more explicit among leaders, more implicit among potential followers. The greater they believe the potential gains to be, the more justifiable violence is likely to appear to them.

There are, however, shortcomings in the model as it stands. Most significantly, it does not take into account psychological and sociological factors which may influence conflict behavior. Lewis Coser (1964: 59) notes that "conflict may be motivated by two distinct yet intermingled factors-a realistic conflict situation and the affective investment in it."

The potential psychological and sociological benefits of engaging in conflict behavior are many. Psychological frustrations or emotional factors may act as an instigation to aggression. Certain conflict strategies might be considered beneficial in that they allow the actor to express these feelings. Leonard Berkowitz (1962: 220) suggests:

Aggression can be gratifying because it involves the expression of an acquired aggressive motive, and/or it signals the reduction of internal conflict, and/or it may restore self-esteem.... It may also be that some of the pleasure following the display of aggression results from the completion of a previously interrupted aggressive response sequence. The interruption created tension, and the completion of the sequence brought about a decrease in the disturbing internal excitement.

Scott (1970: 87) similarly points out that "the existence of emotional fervor or strong hatred can alter the cost picture 
because of the impact it has on the morale and determination of the antagonists."

In another vein, Coser (1964) writes of the group-binding character of conflict. Thus, individuals may obtain a sense of identity and "belonging" from engaging in conflict as a member of some group. The group may be a relative vague one (e.g., "students") or one which is more clearly defined (the U.S. Marine Corps). States Coser (1964: 35): "It seems to be generally accepted by sociologists that the distinction between 'ourselves, the we-group, or the in-group, and everybody else, or the others-groups, out-groups' is established in and through conflict." More abstract benefits, such as a sense of self-satisfaction at doing what one considers morally correct, or socially legitimate, may also be important motivating factors in a conflict situation (compare Gurr, 1970: chs. 6 and 7).

In the model itself, the type of benefits described above differ from $B_{g}$ in that their realization may well be independent of the outcome of the conflict. The term $D_{i}$, then, is defined as the benefit an actor receives from engaging in a particular conflict behavior act regardless of the outcome of the event.

In contrast to $D_{i}$, there are various costs of a psychological or sociological nature which may be associated with certain conflict events. Because psychological costs are always involved in the use of violence, Coser (1967: 107) notes, "it is expected that only relatively small numbers of men will at any time be ready to engage in a politics of violence. For only a few will the psychic gains of violence outweigh the costs." A pacifist, for example, would consider engaging in violent conflict as being extremely costly in a moral and psychological sense. Revolutionary ideologies are likely to offer normative justification for violence and hence rationalize away the moral costs of violent conflict behaviors.

Social costs are also important to consider. One cost of participating in clandestine operations may be social isolation and personal sacrifice for many months. For example, RAND Vietnam interviews (see Leites and Wolf, 1970: 43) report that a Viet Cong defector gave these reasons for changing sides: 
I thought that in fighting on the GVN side, a soldier may be happy because he has a good salary and even though he dies on the battlefield, he dies with a full stomach. On the contrary, a VC soldier usually eats at 3 p.m. a rice bowl as small as that [the subject described it with his fingers] and he walks all night long to fight and to die with an empty stomach.

It is, therefore, necessary to give a broader interpretation to $C_{i}$ so that it includes psychological and sociological costs as well as resource outlays. Thus, the equation for determining the SEU of a given conflict behavior is:

$$
\mathrm{SEU}=\left(\sum_{\mathrm{g}=1}^{\mathrm{n}} \mathrm{B}_{\mathrm{g}} \mathrm{P}_{\mathrm{g}}-\sum_{\mathrm{j}=1}^{\mathrm{m}} \mathrm{A}_{\mathrm{j}} \mathrm{P}_{\mathrm{j}}\right)-\mathrm{C}_{\mathrm{i}}+\mathrm{D}_{\mathrm{i}}
$$

That there are costs and benefits which affect conflict behavior is evident in the following passage from the tactical manual published in connection with the 1971 May Day antiwar demonstrations: "The aim of the Mayday actions is to raise the social cost of the war to a level unacceptable to America's rulers. To do this, we seek to create the specter of social chaos while maintaining the support or at least toleration of the broad masses of American people" (New. York Times, 1971). Thus, the May Day leaders (notably, Rennie Davis) were concerned with stopping the Vietnam war not by raising the government's material costs, but by increasing the social costs of American involvement in Southeast Asia. Violent demonstrations were eschewed as being too costly in both moral and strategic senses. Moreover, the demonstrators were aware that they must minimize the social costs of their own behavior: they sought to maintain "the support or at least toleration" of the mass public. The May Day demonstrators, then, were acting as both strategists and managers. They sought to raise the level of conflict in one social context (Washington, D.C.) in order to limit the intensity and scope of conflict behavior elsewhere (Southeast Asia).

The May Day leaders' strategy, ironically, bears similarities in 
some respects to the Johnson Administration's attempts to coerce North Vietnam. In this instance, the Administration was concerned with increasing the costs to the Democratic Republic of Vietnam (DRV) of infiltration of South Vietnam. Consider this summary from the Pentagon Papers (1971: vol. 4, p. 1) of a memo from Secretary of Defense Robert McNamara dated July 30, 1965:

Future bombing policy should emphasize the threat, minimize DRV loss of face, optimize interdiction over political costs, be coordinated with other pressures on the DRV, and avoid undue risks of escalation.

Thus far, this section has presented a simple SEU maximization approach to the study of decision-making within conflict situations. If one were to focus on a single decision in a conflict-e.g., a "turning-point" in a crisis-then this approach might be particularly useful (compare Allison, 1969; Tanter, 1972). On the other hand, strategists and managers must often be concerned with conflict which occur over time. This fact adds two complexities to the simple SEU model: ${ }^{3}$ first, the utilities associated with various goals and activities may vary over time; and, second, the subjectively estimated probabilities may be altered as a conflict develops.

The problem of utilities changing over time can be handled with relative ease. The SEU model simply assumes that the decision is based on the utilities that existed at the time the decision was made. Utilities are free to change between decisions so long as the actor uses his most recent utility assessments in determining his actions.

Probability alteration over time is somewhat more complex. An initial subjectively estimated probability (or probability distribution) may be based on very sketchy information. As a conflict progresses over time, however, and as various strategic moves are attempted, additional information is generated regarding the conflict situation as a whole. The question is: How should such information be processed to allow the reevaluation of one's subjective probabilities? 
What is required is some method of determining a new (or posterior) subjective probability, given some previous (or prior) estimate plus some new information. The optimal solution to this problem involves Bayes' theorem. Elementary probability theory defines $P(D \cap H)$ as being equal to $P(D \mid H) P(H)$. That is, the probability that both one's information about the "true state" and one's own hypothesis about this state are true is equal to the probability of the information, given the hypothesis, multiplied by the probability that the hypothesis is true. Some algebraic manipulation leads to a basic form of Bayes' theorem:

$$
P(H \mid D)=\frac{P(D \mid H) P(H)}{P(D)}
$$

(provided that $\mathrm{P}(\mathrm{D})$ and $\mathrm{P}(\mathrm{H}) \neq 0$ ).

A somewhat contrived, although not entirely unrealistic example may be helpful in understanding how Bayes' theorem might be employed:

Two insurgent leaders are working together. One, $I_{1}$ believes that if they engage in activity, $\mathrm{A}$, there is a .4 chance that the government, $G$, will respond in a certain way. $I_{2}$, however, believes that $G$ probably will respond, and he assigns .7 to this probability. Either $I_{1}$ or $I_{2}$ is correct. $I_{1}$ has, in the past, been quite expert at outguessing $G$, so the probability that he is right is set at .8 . The probability that $I_{2}$ is correct, then, is $1.0-.8$, or .2. The insurgents engage in activity $A$ and, sure enough, $G$ responds. How should $I_{1}$ and $I_{2}$ revise their estimates of who is right in light of this datum?

Once again, Bayes' theorem states that:

$$
P(H \mid D)=\frac{P(D \mid H) P(H)}{P(D)}
$$

where $\mathrm{P}(\mathrm{D})=\Sigma \mathrm{P}(\mathrm{D} \mid \mathrm{H}) \mathrm{P}(\mathrm{H})$.

$\mathrm{P}\left(\mathrm{D} \mid \mathrm{H}_{1}\right)$ is the probability of the government responding, given that $I_{1}$ is correct. This probability, we know, is .4. Similarly, $\mathrm{P}\left(\mathrm{D} \mid \mathrm{H}_{2}\right)=$.7. Moreover: 


$$
\begin{aligned}
& \mathrm{P}\left(\mathrm{H}_{1}\right)=.8 \\
& \mathrm{P}\left(\mathrm{H}_{2}\right)=.2
\end{aligned}
$$

By substitution, then:

$$
\begin{aligned}
\mathrm{P}\left(\mathrm{H}_{1} \mid \mathrm{D}\right) & =\frac{(.4)(.8)}{(.4)(.8)+(.2)(.7)} \\
& \approx .70 \\
\mathrm{P}\left(\mathrm{H}_{2} \mid \mathrm{D}\right) & =\frac{(.2)(.7)}{(.4)(.8)+(.2)(.7)} \\
& \approx .30
\end{aligned}
$$

Thus, the insurgents have become slightly less confident that $I_{1}$ is correct and correspondingly less sure that $I_{2}$ is wrong. This is certainly what one would expect, given the datum. This example is simplified in that it deals with point estimates of probabilities rather than with continuous probability distributions. Nevertheless, the basic logic of the process is the same in both instances (see, for example, Edwards et al., 1963).

The next question which one might ask is whether this Bayesian model of information-processing reflects accurately what occurs within the dynamics of a conflict situation. The answer is that it almost certainly does not. There is, in fact, a good deal of experimental work which has shown that human beings tend to be "conservative" information processors when compared with what one would expect from Bayes' theorem (Edwards, 1968; Phillips and Edwards, 1966; Peterson et al., 1965).

If one is concerned with how strategists and managers should process the information generated within the context of a conflict, then Bayes' theorem is quite germane. If, on the other hand, an accurate description of information-processing is desired, then it is clear that psychological and other factors must be taken into account to explain the conservative nature of human beings. This topic we must leave for discussion elsewhere (see Edwards, 1968). 


\section{IMPLICATIONS FOR ANALYSIS}

This essay suggests that it may be useful to consider conflict situations as instances in which actors employ behaviors which tend to maximize expected gains and minimize expected losses. Moreover, we have pointed out that these gains and losses may be related to factors other than the particular conflict of interest. It is one thing to make such assertions, however, and quite another to utilize such an approach empirically. A model which considers sociopsychological aspects of a conflict situation within a framework of utility maximization is clearly difficult to operationalize entirely. This does not imply that the model is useless or irrefutable, however; a number of avenues for research are potentially useful for the evaluation of the model and its implications.

One possibility lies in the study of decision-making within experimental settings. Experimental research on SEU and similar axiomatic models of decision-making is well developed. Most of these experiments focus on decisions about bets, but the inferential step to decisions regarding other forms of risky outcomes is not large. Problems which appear at first to be insurmountable, such as the quantification of utilities and subjective probabilities, have been shown to be soluble with a little imagination and insight. Excellent bibliographies of relevant literature are found in two works by Edwards (1961, 1954a).

An important development in conflict research would be to combine decision-making experiments with more explicitly social psychological investigations dealing with conflict behavior. Berkowitz $(1969,1965,1962)$ has written extensively about the latter type of research. The kind of investigation we are advocating might examine, for instance, differences in the nature of decisions made at different levels of psychological frustration. Other experiments, similar to those conducted in small-group research, could examine the decision processes of individuals in isolation and within different group contexts. Such experimentation would certainly be useful in uncovering 
evidence about the behaioral modifications necessary to make decision theory more descriptive of conflict dynamics.

Another type of model evaluation might employ aggregate data on domestic turmoil (Feierabend and Feierabend, 1966; Gurr, 1968b; Tanter, 1969; Markus and Nesvold, 1972). By examining the success over time of various conflict behaviors along with indicators of systemic frustration, relative deprivation, and the like, one might ascertain the comparative importance of "nonrealistic" (i.e., sociological, psychological, and so on) factors versus "realistic" (i.e., conflict of interestrelated) factors in explaining conflict behavior.

The systematic analysis of particular cases might also serve to evaluate the utility of the conflict model proposed here (Wedge, 1969). An in-depth study of how strategists and managers behaved within particular contexts could aid greatly in the understanding of decision-making in conflict situations.

Another approach would employ survey techniques to gather information on individual attitudes about conflict as well as information on the personal experiences of persons in situations of political conflict (Levy, 1970; Cantril, 1965). Such a study might uncover the psychological correlates of participation in conflict behaviors of varying intensities. Moreover, one could examine the ways in which individuals who participate in political conflict differ from those who do not. Data gathered in this way could also indicate whether individuals attempt to weigh the costs and benefits of their potential actions during times of conflict.

Thus, there are a number of methods available to evaluate the validity of the conflict model proposed here. No single approach is necessarily more powerful than any other. Rather, the use of multiple streams of evidence gathered through a number of techniques is the most desirable manner of ascertaining the descriptive value of the SEU model of conflict decision-making.

\section{CONCLUSIONS}

What, then, are the implications of this model of conflict 
behavior? By assuming a rational component of conflict, the model implies that conflict behaviors-including violent onesmay be engaged in by reasonable men. Thus, conflict is an inevitable occurrence in social life, and violent strategies are often continuations of a general bargaining process among competing actors. Nieburg (1969: 81) makes the point well when he writes:

The "rational" goal (in the behavioral sense of maximizing assets and options) of the threat of violence is accommodation of interests, not provocation of actual violence. Similarly, the "rational" goal of actual violence is demonstration of the will and capacity of action, establishing a measure of the credibility of future threats, not exhausting that capacity in unlimited conflict.

Managers must recognize that conflict is unavoidable and that often it has an objective basis in reality-namely, the incompatibility of the goals of the actors involved. This is not to say that efforts to ease frustration, vent instinctive drive harmlessly, or increase mutual understandings are not beneficial. Such efforts can indeed serve either to prevent unnecessary conflict or to keep conflict behaviors within certain bounds of intensity. The point is that conflicts of interest are inevitable; in such instances the manager must focus on how to regulate the scope or intensity of conflict by manipulating the costs and benefits associated with the range of potential behaviors. As Gurr (1970: 156) notes, "the greater the utility people attribute to tactics of violence in getting what they want, the more readily they will resort to political violence." Put another way, the task of the conflict manager is to affect the utility of violence so that people will find it advantageous to employ other tactics. Elsewhere in this issue, Fink presents a lucid discussion of options available to conflict managers; comments in this essay, therefore, will be brief (see also Gurr, 1970: 352-357).

It should be apparent, however, that to a society the continued suppression of conflict is at least as dangerous as its violent manifestation. A total lack of conflict representation is as undesirable as the sole use of violent confrontation to resolve 
conflict. For the conflict manager to prevent these extremes of the "spectrum of political options" from overwhelming the center, he must maintain the efficacy and legitimacy of those modes of political action which minimize violence and facilitate social change (Nieburg, 1969: 159-160). This philosophy is echoed in "The Port Huron Statement," (Jacobs and Landau, 1966: 156) which established the early guidelines for the Students for a Democratic Society. It reads, in part:

In social change or interchange, we find violence to be abhorrent because it requires generally the transformation of the target, be it a human being or a community of people, into a depersonalized object of hate. It is imperative that the means of violence be abolished and the institutions-local, national, international-that encourage nonviolence as a condition of conflict be developed.

The manager can affect the utility of violence in two ways. One way, just mentioned, is to increase the utility of nonviolent strategies. The other method, probably more common, is to decrease the utility of violent strategies. One approach involves establishing a pattern of coercive control or negative sanction. If sanctions are applied clumsily or inequitably, however, they may have the effect of increasing rather than decreasing future violence (Gurr, 1970, 1968b; Leites and Wolf, 1970; Markus and Nesvold, 1972). If the level of sanctions is perceived as being inequitable or unjust, then the legitimacy of the managereither civilian or governmental-may be undermined.

This consequence leads to another management option. The conflict manager can attempt to affect the social and psychological justifications for violence. In this regard, Gurr (1970: 352) notes: "a ruling elite can reduce the likelihood of violence against itself by symbolically reinforcing its legitimacy, censoring those who agitate against it, and providing diversionary means for the expression of hostility." Similarly, civilian managers can enhance their impact and respond to governmental strategists by emphasizing the legitimacy of their demands and the basis of their social support.

The strategist should be aware that in the long run violence 
may not be beneficial to him, although it may bring immediate gain. As already stated, the rational goal of violence is the demonstration of a capacity for action, establishing a measure of credibility for future threats, not the exhaustion of that capacity. Thus, the strategist should attempt, by establishing his credibility, to increase the costs to the target of ignoring future demands to resolve a conflict. In this way, the strategist may resort to violence so that less extreme modes of conflict resolution will become more effective.

Additionally, the strategist should be aware that "nonrealistic" considerations may be coloring his decision to increase the scope or intensity of conflict. Whether the strategist will or even can account for-and thereby regulate-these factors is difficult to answer. Nevertheless, the strategist may want to consider if intensifying the level of conflict behavior is likely to resolve the conflict of interest or solely benefit him in other, perhaps more personal, ways.

Finally, the strategist may engage in a particular conflict behavior precisely because of its "nonrealistic" utility. For example, the integrative effect of group conflict behavior has been touched on earlier. A conflict behavior may be chosen not because it is particularly likely to achieve long-term goals, but because it may bind the group together and thereby increase the likelihood of success in later actions.

Some would argue that recent manifestations of conflict within the United States have been qualitatively different from conflict behaviors of the previous decade. Among students and blacks, in particular, there seems to be an increasing awareness of the necessity to coolly and "rationally," if you will, assess the cost-benefit parameters of conflict behaviors. Younger strategists, for example, caution not to engage in action as part of an "ego trip"; they urge that people attempt to "get it together" or pause to evaluate the nature of the conflict. In any event, strategists and managers must recognize the costs of both protracted violence and refusal to bargain over conflicts of interest. One must hope that a better understanding of decision-making in conflict situations will allow competing 
actors to resolve conflicts before violent confrontation becomes a necessary, if not attractive, tactic.

\section{NOTES}

1. For expository convenience, the SEU model has been decomposed to display the benefits and costs comprising the model. Usually the model is presented in a form similar to the EV equation described earlier.

2. The example assumes a linear utility for money function.

3. An additional potential complexity should also be mentioned. A number of theorists have argued that the variance and even higher moments of a utility distribution are as important as its SEU in determining a decision. Edwards (1954a: 401) offers this example: "You would probably prefer the certainty of a million dollars to a 50-50 chance of getting either four million or nothing. I do not think this preference is due to the fact that the expected utility of the $50-50$ bet is less than the utility of one million dollars to you, although this is possible. A more likely explanation is simply that the variances of the two propositions are different. Evidence in favor of this is the fact that if you knew you would be offered this choice 20 times in succession, you would probably take the 50-50 bet each time."

Experimental research, however, shows that the issue of variance preference is not at all straightforward (compare Edwards, 1954b; Royden et al., 1959; Coombs and Pruitt, 1960). For this reason, this essay leaves the topic of variance preferences to one side.

\section{REFERENCES}

ALLISON, G. T. (1969) "Conceptual models and the Cuban missile crisis." Amer. Pol. Sci. Rev. 63: 689-718.

ARDREY, R. (1966) The Territorial Imperative. New York: Atheneum.

-- (1961) African Genesis. New York: Atheneum.

AXELROD, R. (1970) Conflict of Interest. Chicago: Markham.

BANDURA, A., D. ROSS, and S. ROSS (1963) "Vicarious reinforcement and imitative learning." J. of Abnormal and Social Psychology 67: 601-607.

BERKOWITZ, L. (1969) "Social motivation," pp. 50-118 in G. Lindzey and E. Aronson (eds.) Handbook of Social Psychology. Volume 3. Reading, Mass.: Addison-Wesley.

--- (1965) Advances in Experimental Social Psychology. Volume 2. New York: Academic Press.

--- (1962) Aggression: A Social Psychological Analysis. New York: McGraw-Hill. BERNARD, J. (1957) "The sociological study of conflict," in International Sociological Association, The Nature of Conflict: Studies on the Sociological Aspects of International Tensions. Paris: UNESCO. 
BOULDING, K. E. (1962) Conflict and Defense: A General Theory. New York: Harper.

BUSS, A. H. (1961) The Psychology of Aggression. New York: John Wiley.

CANTRIL, H. (1965) The Pattern of Human Concerns. New Brunswick, N.J.: Rutgers Univ. Press.

COOMBS, C. H. and D. G. PRUITT (1960) "Components of risk in decision making: probability and variance preferences." J. of Experimental Psychology 60: 265-277.

COSER, L. A. (1967) Continuities in the Study of Social Conflict. New York: Free Press.

-- (1964) The Functions of Social Conflict. New York: Free Press.

DAVIES, J. C. (1962) "Toward a theory of revolution." Amer. Soc. Rev. 27: 5-19.

DAVIS, M. D. (1970) Game Theory: A Non-technical Introduction. New York: Basic Books.

DOLLARD, J., L. W. DOOB, N. E. MILLER, O. H. MOWRER, and R. R. SEARS (1939) Frustration and Aggression. New Haven, Conn.: Yale Univ. Press.

DOWNS, A. (1957) An Economic Theory of Democracy. New York: Harper \& Row. EDWARDS, W. (1968) "Conservatism in human information processing," pp. 17-51 in B. Kleinmuntz (ed.) Formal Representation of Human Judgement. New York: John Wiley.

--- (1961) "Behavioral decision theory." Annual Rev. of Psychology 12: 473-498.

-- (1955) "The prediction of decisions among bets." J. of Experimental Psychology 51: 201-214.

-- (1954a) "The theory of decision making." Psych. Bull. 51: 370-417.

-- (1954b) "Variance preferences in gambling." Amer. J. of Psychology 67: 441-452.

-- and A. TVERSKY (1967) Decision Making. Middlesex, Eng.: Penguin.

EDWARDS, W., H. LINDMAN, and L. D. PHILLIPS (1965) "Emerging technologies for making decisions," pp. 261-325 in New Directions in Psychology II. New York: Holt, Rinehart \& Winston.

EDWARDS, W., H. LINDMAN, and L. J. SAVAGE (1963) "Bayesian statistical inference for psychological research." Psych. Rev. 70: 193-242.

FEIERABEND, I. K. and R. L. FEIERABEND (1966) "Aggressive behaviors within polities, 1948-1962: a cross-national study." J. of Conflict Resolution 10: 249-271.

--- and B. A. NESVOLD (1969) "Social change and political violence: cross-national patterns," pp. 632-687 in H. D. Graham and T. R. Gurr (eds.) The History of Violence in America. New York: Praeger.

FINK, C. (1968) "Some conceptual difficulties in the theory of social conflict." J. of Conflict Resolution 12: 412-460.

GURR, T. R. (1970) Why Men Rebel. Princeton: Princeton Univ. Press.

-_- (1968a) "Psychological factors in civil violence." World Politics 20: 245-278.

-- (1968b) "A causal model of civil strife: a comparative analysis using new indices." Amer. Pol. Sci. Rev. 62: 1104-1124.

HARSANYI, J. C. (1969) "Rational-choice models of political behavior versus functionalist and conformist theories." World Politics 21: 513-538.

HUNTINGTON, S. P. (1968) Political Order in Changing Societies. New Haven, Conn.: Yale Univ. Press. 
JACOBS, P. and S. LANDAU (1966) The New Radicals: A Report with Documents. New York: Vintage.

KELMAN, H. C. (1965) International Behavior: A Social Psychological Analysis. New York: Holt, Rinehart \& Winston.

KORNHAUSER, W. (1959) The Politics of Mass Society. New York: Free Press.

LEITES, N. and C. WOLF, Jr. (1970) Rebellion and Authority. Chicago: Markham.

LERNER, D. (1963) "Toward a communication theory of modernization," pp. 327-350 in L. Pye (ed.) Communications and Political Development. Princeton: Princeton Univ. Press.

LEVY, S. G. (1970) "The psychology of political activity." Annals of Amer. Academy of Pol. and Social Sci. 391: 83-96.

LORENZ, K. (1966) On Aggression. New York: Harcourt.

LUCE, R. D. and H. RAIFFA (1957) Games and Decisions. New York: John Wiley.

MACK, R. W. and R. C. SNYDER (1967) "The analysis of social conflict-toward an overview and synthesis." J. of Conflict Resolution 1: 212-248.

MARKUS, G. B. and B. A. NESVOLD (1972) "Governmental coerciveness and political instability: an exploratory study of cross-national patterns." Comparative Pol. Studies 5 (July).

MILLER, N. E. (1941) "The frustration-aggression hypothesis." Psych. Rev. 48: 337-342.

NARDIN, T. (1971) "Theories of conflict management." Peace Research Reviews 4, 2: $1-93$.

NASUTION, A. H. (1965) Fundamentals of Guerrilla Warfare. New York: Praeger.

New York Times (1971) May 3: 41 (column 1).

NIEBURG, H. L. (1969) Political Violence: the Behavioral Process. New York: St. Martin's Press.

--- (1963) "The uses of violence." J. of Conflict Resolution 7: 43-55.

-- (1962) "The threat of violence and social change." Amer. Pol. Sci. Rev. 56: 865-873.

OLSON, M., Jr. (1968) The Logic of Collective Action: Public Goods and the Theory of Groups. New York: Shocken.

The Pentagon Papers (1971) Senator Gravel edition, Volume 4. Boston: Beacon.

PETERSON, C. R., R. J. SCHNEIDER, and A. J. MILLER (1965) "Sample size and the revision of subjective probabilities." J. of Experimental Psychology 69: 522-527.

PHILLIPS, L. and W. EDWARDS (1966) "Conservatism in a simple probability inference task." J. of Experimental Psychology 72: 346-354.

RAPOPORT, A. (1970) N-Person Game Theory: Concepts and Applications. Ann Arbor: Univ. of Michigan Press.

--- (1966) Two-Person Game Theory: The Essential Ideas. Ann Arbor: Univ. of Michigan Press.

--- (1960) Fights, Games, and Debates. Ann Arbor: Univ. of Michigan Press.

RIKER, W. H. and P. C. ORDESHOOK (1968) "A theory of the calculus of voting." Amer. Pol. Sci. Rev. 62: 25-42.

ROYDEN, H. L., P. SUPPES, and K. WALSH (1959) "A model for the experimental measurement of the utility of gambling." Behavioral Sci. 4: 11-18.

RUSSETT, B. M. (1964) "Inequality and instability: the relation of land tenure to politics." World Politics 16: 442-454. 
SAVAGE, L.J. (1954) The Foundations of Statistics. New York: John Wiley.

SCOTT, A. M. (1970) Insurgency. Chapel Hill: Univ. of North Carolina Press.

SHAPIRO, M. J. (1969) "Rational political man: a synthesis of economic and social-psychological principles." Amer. Pol. Sci. Rev. 63: 1106-1119.

STORR, A. (1968) Human Aggression. New York: A theneum.

TANTER, R. (1972) "International system and foreign policy approaches: implications for conflict modelling and management," in R. Tanter and R. Ullman (eds.) Theory and Policy in International Relations. World Politics supplementary issue, Spring 1972.

-- (1969) "International war and domestic tumoil: some contemporary evidence," pp. 550-569 in H. D. Graham and T. R. Gurr (eds.) The History of Violence in America. New York: Praeger.

--- and M. MIDLARSKY (1967) "A theory of revolution." J. of Conflict Resolution 11: 264-280.

WEDGE, B. (1969) "The case study of student political violence: Brazil, 1964, and Dominican Republic, 1965." World Politics 21: 183-206.

WILSON, J. Q. (1961) "The strategy of protest: problems of Negro civic action." J. of Conflict Resolution 5: 291-303. 